Journal of Social Sciences 7 (2): 132-140, 2011

ISSN 1549-3652

(C) 2010 Science Publications

\title{
Ethics Camp: The Appropriate Management Model for Northeastern Region Youth, Ecclesiastical Region 9
}

\author{
Wongsathit Wisupee, Sastra Laoakka and Kosit Paengsoi \\ The Research Institute of North Eastern Arts and Culture, \\ Mahasarakham University, Maha sarakham, 44000 Thailand
}

\begin{abstract}
Problem statement: Youth's ethics tended to be a continuous increased problem and they were in their age without judgment. Youths were very important for national development in future, if their problems were not urgently solved it would overall effect to way of live in their families, communities, socials and Thailand. Approach: This research aimed to study backgrounds, current conditions, problems on management and the appropriate management model of Ethics Camp for the Northeastern Region Youth, Ecclesiastical Region 9. The study was a qualitative research conducted in 4 provinces 1 place of the Northeastern Region Youth, Ecclesiastical Region 9 and Thailand. Observation form, survey form, interview form, focus group discussion and study shop were used as research tools. Triangulation was used to test all data and data was analyzed by descriptive research. Results: The result founded that the background in overall of 4 places were began by making study trips of directors or lecturing monks at famous camp and they, later, brought those models back to establish ethics camps in their own provinces. For current conditions and problems, it was found that; in aspect of personnel-there was lacking of competent personnel, in aspect of budget-there was lacking of budget for expenses, in aspect of material-some place had old and damaged equipments, in aspect of management-there was not enough budget for long-term training and also lacking of lecturing monks, in aspect of marketing-there was lacking of public relation and distinct documents of courses and in aspect of technological innovation-lecturing monks had no knowledge to produce modern technological media. For appropriate management model, it was found that; in aspect of personnel-camp directors should have wide and long vision, intelligence, perseverance, honesty and human relation while lecturing monks must be professional; in aspect of budget-charges for any expenses should be depended on situations; in aspect of financial management-should be in form systematic study with committees and asked for supporting from related agencies; in aspect of material-should have safety, cleanliness and peace that was good environment for training while training equipments should be modern, attractive and met requirements of trainees; in aspect of operations as course analysis-should analyze the appropriateness of trainees' age, maturity and requirement, course development-other subjects should be integrated into training courses, training operation-should be trained in form of demonstration, evaluation-should be conducted by observation, document and expression feeling in trainees' mind; in aspect of marketing-should provide services with friendliness and publicized camps in websites ; in aspect of technological innovation-should produce modern media, apply for the appropriateness of trainees' maturity and also analyze such media before using. Conclusion/Recommendations: Ethics Camp for Northeastern Region Youth, Ecclesiastical Region 9 should be cooperated by all net study to support youth for attending ethics camp to develop their better quality of life.
\end{abstract}

Key words:Ethics camp, training equipments, appropriate management model, ecclesiastical region 9, punyanuntaram Temple, northeastern region youth, weruwan meditation

\section{INTRODUCTION}

Nowadays, way of life in the era of advanced knowledge and technology was rapidly changed from simple to chaos and competition everywhere.
Materialism had influences in social made ethics, which used to control human thinking and actions, be ignored or forgot. Many of people did not know its importance and thought that it did not support material growth. This reflected living of people in social, who did not cling to

Corresponding Author: Wongsathit Wisupee, The Research Institute of North Eastern Arts and Culture, Mahasarakham University, Maha Sarakham, 44000 Thailand Tel: +66-43-721686 


\section{J. Social Sci., 7 (2): 132-140, 2011}

ethics as a guideline of their way of life, was in suffering. For groups of people who had long vision, they thought that such situation would lead social to deterioration as happened in other socials. They called for restoration of ethics especially in youth who would become adults.

Not only youth but also adults were not interested in religion and ethics and that was a general condition of social. However, those who had social responsibility in education circle turned to pay more attention to religion and ethics especially in 10-20 years before. They said about problems of religion and ethics that they should be stress in education. This meant that there was deficiency or defection of these matters. This conformed to speech of Phra Dhamma Kittiwong as "Now, there are many problems in aspect of ethics and morality. It is serious and critical that people stay away from temples, no ethics and morality in educational curriculum and disunity in families. In this situation, therefore, government must have distinct policies by utilizing Buddhist Dhamma to solve those problems and to develop the country for further prosperity" (Suksri et al., 2010).

In context of northeastern region under the jurisdiction of Ecclesiastical Region 9, there were 4 provinces as Khon Kaen, Mahasarakham, Kalasin and Roi Et. Most of them were important provinces in many aspects such as; Khon Kaen and Mahasarakham were educational centers with several of university that made many of students or youths went to study. Growth of material, technology and craziness of foreign cultures induced them to bad things as skipping class, addicting video games and sex, gambling, quarrel and fight and also addicting drugs, that conformed to an interview of an educator. Khon Kaen Educational Service Area Office 1 found that skipping class was the most problem and the next was gambling as snooker and football, gathering for unlawful purpose in rent rooms, carrying weapons and addicting many kinds of drug that conformed to an educator cited some data about social problems. He said that youths who broke the rule were intractable children, beggars and those who skipped their class. The most serious case they did was breaking a law on; attacking, stealing, raping and infringed the law about pistol, bullet and explosive.

Their infringements were caused by internal and external factor. Internal factor was caused by them divided into; biological factor was physical impairment such as disorder of brain or glands, mental factor was emotional impairment such as mental deficiency. External factor was caused outside them that drove or guided them to break the rule, it was environmental and social causes divided into 4 aspects; family-family had influences on learning and social adaptation of children. Important social problems were children and youths infringement, drugs and crimes that most of them were all rooted from broken family; educational environment-when children from different family came together them would receive bad influences from their bad friends to mislead them; neighborhood and communal environment-social and cultural condition had influences on behaviors of children who lived in the same neighborhood and community together with people in that it would have same conduct and culture; mass media environment-movie, radio, television, fiction, computer and internet had great influences on infringement of children and youth. Mass media was a two-edged sword. If they had not good judgment they would copy bad things, so parents should pay more attention on this matter (Suksri et al., 2010).

From current conditions and problems of children and youths under the jurisdiction of Ecclesiastical Region 9 in all of 4 provinces, it reflected problems of the country that tended to be more violent and effected to social system in overall. Due to children and youths were resources and future of our nation, hence, providing them with good future must be responsibility of all sectors in social; religion, family, government, education, public health, life, labor and welfare; to aware and place importance on them. Data system development for standard and continuous stipulating strategic policies was an important concern and agenda of all related parties. There were management models in many aspects such as ethics camp that promoted students or youths to have activities with temples. These activities might be took place in temples or schools, but they should let students to participate. Students would be promoted with ethics and good conducts as national youth. Therefore, previous problem conditions and ethics camp management could not be solved. Moreover, ethics camp directors lacked of good management and also lacking of communities and related agencies integration effected to the development. These effected to the development of those camps for better changing of youth's behavior and needed to have a research with objectives to study backgrounds of Ethics Camp and to study current conditions, problems and management model development of Ethics Camp for Northeastern Region Youth, Ecclesiastical Region 9.

\section{MATERIALS AND METHODS}

Research method: This study was a Research and Development (R and D) by using qualitative research (Laomi et al., 2009; Poo-Inna et al., 2009). 


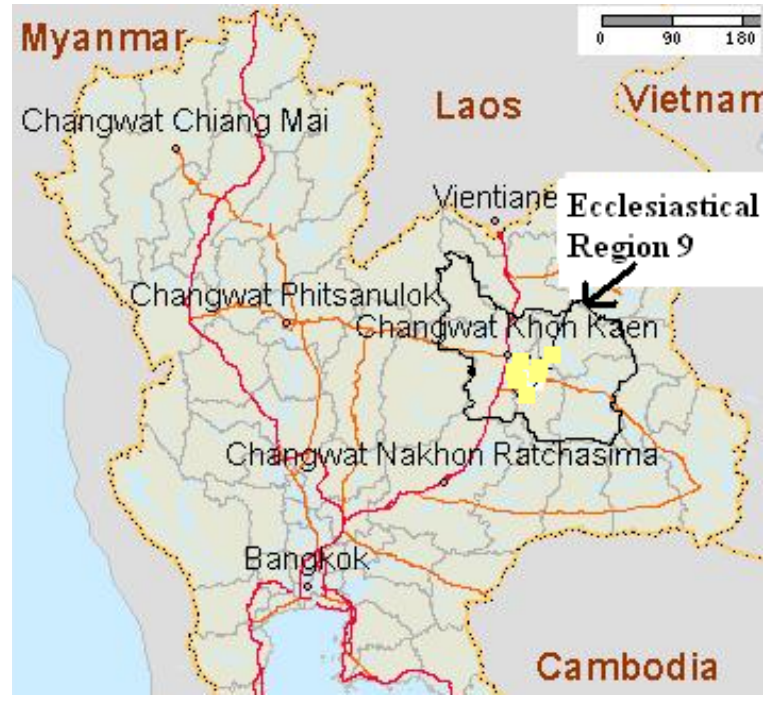

Fig. 1: Location map of the Ecclesiastical Region 9

Population and samples was people who lived in 4 provinces; Khon Kaen, Mahasarakham, Kalasin and Roi Et; under the jurisdiction of Ecclesiastical Region 9 (Fig. 1). Sample related with this research were 164 persons consisted of 40 key informants, 80 casual informants and 44 general informants. Research areas were in 4 provinces 1 place for each. Survey forms, observation forms, interview forms, focus group discussions and studyshops were used as research tools. Data was collected from documents, research reports, laws, policies, strategies and field study data. Validity, reliability and triangulation were used to test all data and it was analyzed by conclusion, classification and comparison in accordance with research aims.

\section{RESULTS}

Background: It was found that each of 4 ethics camps; Weruwan Meditation Center, Khon Kaen; Chaloem Phrakiat Mind Development Center, Wat Sri Sawat, Mahasarakham; Chaloem Phrakiat Mind Development Center, Wat Pracha Niyom, Kalasin; Chaloem Phrakiat Mind Development Center, Wat Pa Nong Mong Buraparam, Roi Et; had not any training in form of project as the present. In the past, focus point of Buddhism propagation was meditation that all participants must wear white clothes, observe religious precepts in Buddhist days or festivals and conduct meditation and praying. Later, some ethics camp as Wat Chuchit Dhammaram, Phra Nakhon Si Ayutthaya started to be famous with lecturing monks training to against drugs by Phra Archarn Werapun Rukkitselo in 1999-2001, the time of heavy drug invasion in educational institutes. This made general people accept the fame of Wat Chuchit Dhammaram. Other places were ethics camps of Wat Punya Nuntaram, Pathum Thani and Wat Chonprathan Rangsarit, Nonthaburi that directed by a great monk Punya Nunta Bhikkhu. He applied model of the ethics camp directed by his teacher Buddhadasa Bhikkhu to establish his own model. After that, camp directors from many provinces attended training and making study trips for applying with their own contexts.

Current conditions and problems: In aspect of personnel, it was found that there was no problem on camp directors because they seriously studied and paid attention to disseminate Ethics Camp Project Model. In aspect of lecturing monks, it was found that some of them lacked of professionalization, skills and experiences because of new ones. For their behavior, it was found that some of them did not clearly understand objectives of Buddhism propagation in form of ethics camp. For their punctuality, it was found that some of them spent more time than their responsibilities that made other activities be postponed. For their psychological methods, it was found that some of them applied less of psychology in training, could not solve problems and had no motivation for trainees. In aspect of personnel net study, it was found that student and teacher net study did not continued their trained activities in schools. After finishing of training for 3-4 months, most of student turned to their previous condition.

In aspect of training venues, it was found that they were overall in good condition but there was some problem about water leakage on roofs of both building at Weruwan Meditation Center that disturbed training. For accommodations, it was found that there was not enough at Wat Sri Sawat and trainees had to sleep at a pavilion for funeral praying. . For toilets, it was found that there was not enough for trainees. For almshouses or kitchens, it was found that there was not individual one at Wat Pracha Niyom and Wat Pa Nong Mong Buraparam. There was not enough space for frequent increased trainees at Weruwan Meditation Center. For training equipments, it was found that some camps had ruined media, amplifier, wireless microphone, overhead projector, as well as very thin of white clothes.

In aspect of course analysis, it was found that there was a changing of curriculum that made lecturing monks had to suddenly change their training course. For training durations, it was found that there were not enough budgets for long-term training. For trainee specification, it was found that some students broke camp's rule by escaping from camps for training operations, it was found that there was lacking of 


\section{J. Social Sci., 7 (2): 132-140, 2011}

lecturing monks that imbalanced with many trainees and sometime there were 2 courses in the same time. For training activities, it was found that some of trainees had no collaboration such as grateful activity needed peace and silence but some students did not pay attention by playing or making fun with their friends. For training equipments, it was found that amplifier, microphone and overhead projector were out of order because of its long services.

In aspect of public relation, it was found that website of some camps were not updated that caused no new information. The most important thing was all camps had not any distinct documents of training courses to be guidelines for other camp or people.

In aspect of media production, it was found that lecturing monks produced very few of technological media because they had no knowledge and time enough to produce modern technological media

The appropriate management model: Personnel management, it was found that camp directors should have wide thinking, long vision, knowledge seeking, daring to think, act, lead and follow. They should have characteristics as long vision, good managing, dependable, intelligence, perseverance, honesty and human relationship.

In aspect of lecturing monks; they should pass some training courses, had both of secular and religious knowledge and could integrate various subjects for training, had skills and experiences for connecting Dhamma with daily life, could explain child and youth for easy understanding and actual practice. For professionalization, they should have starting point, seeking their opportunities for self-development in various fields with continuity to find new things. For pre-training preparation, they should have meeting for planning, allocating responsibilities and equipment preparation. The heart of training was let students having actual practices based on "Tri Sikkha of Sil, Smathi and Punya" (Three studies of Buddhist commandment, meditation and wisdom) and also "Ariya Marka" (Noble path) for their daily life application. For lecturing monks' behavior, they should be a good model, had good human relationship and good friendship. For their punctuality, they should come at least 10 minute before training class and ontime finishing. For their psychological methods, they should recognize nature of trainees; understand trainees' physical, mental and emotional development. Lecturing monks had to be believable and reliable for everyone to follow.

In aspect of personnel net study, lecturing monks and camp directors should have methods to establish lecturing monks' net study by contacting in line of ecclesiastical region to ask for provincial Dhammaduta (Buddhist missionary monk) and monks who taught moral in schools to participate with training as professional lecturers. A committee was appointed in each net study consisted of chairman of lecturing monks net study, vice chairman, treasurer and coordination committee to contact communities' leader as sub-district headman, village headman by inviting them to participate with training activities.

Budget or supporting fund, camps asked for budgets from communities as; provincial administrative organizations, sub-district administrative organizations, municipalities, etchant also government sectors as; provincial Buddhism office and provincial culture office. Operation expenses divided into 4 categories as; material expense, food expense-90 baths per day or 30 baths/head/period and adjustment depended on economy, accommodation expense 3,500-4,000 baths for 2 nights 3 days and lecturing monks expense depended on granters. For financial aspect, there was a transparent accounting system controlled by an accounting committee with 2 of 3 members signature for depositing or withdrawal and also had an audit committee.

In aspect of training venues, accommodations, almshouse and toilets should have sufficiency, cleanliness, tidiness, safety, be far from smell and noise pollution and obviously separate between lady and gent.

For the methods, it should be provided according to the appropriateness of trainees' age, gender, maturity and requirement, especially could apply with their daily life. The appropriated duration of training should be and 2 days 3 nights. For course development, main objective of each course was training students to be good persons with smartness and happiness. Good persons that this world needed were those who had respect, discipline and patience. Smart persons that this world needed were those who could apply "Tri Sikkha of Sil, Smathi and Punya” with their daily life. In aspect of courses content determination, cultural aspect should be low staying but high action. Low staying meant having low profile of living while high action emphasized on importance of etiquette with gentleness both of body and words. There were 7 categories of morality as; patience, perseverance, thriftiness, honesty, discipline and far from bad things. Principle of 5 good for better life were; good thinking, good speaking, good acting, good friend and good place. In aspect of activity, it should focus on the heart of philosopher; "Su, Ji, Pu and Li: listening, thinking, questioning and writing." Training courses had to stress on being good example, good human relationship and good friend. For 
training equipments, training courses should applied form principle of nature, technology and Buddhist way. For training operation, learner-centered instruction should be conducted. On-training observation, article writing and expression feeling of trainees should be use in training sessions.

In aspect of trainees' requirements, courses should have modernity, attractiveness and flexibility in accordance with situations and incidents. Services should be conducted with friendliness and good relationship as well as provided trainees with liaisons. In aspect of public relation, camps should propagate via brochures, books, pamphlets, magazines, community radios and internet.

In aspect of media production, it had main composition as production planning, media production and finding media efficiency. For media application, lecturing monks had to appropriately analyze, edit and use that should consider about the appropriateness of trainees’ age, gender, maturity and requirement.

\section{DISCUSSION}

Background of ethics camp for northeastern region youth, ecclesiastical region 9: Ethics camp establishment at the beginning, there was Buddhism propagation in general model as wearing wear white clothes and observe religious precepts over 3 months of Buddhist lent. That was way of life and social condition of northeastern region for long time. Monks played important role in Buddhism propagation by teaching, training and behaving as a good example. In the past, training model was in form of meditation; wishing happiness to all creatures, listening to sermon and people who attended training was only elder. During 1998-2002 was the beginning of ethics camp because Thailand was in economic regression, floating of Thai currency, weak social, drugs invasion. Target of drugs was youth! Due to weakness of family, community and social youth had no supporters, so they turned to drugs. Therefore, all ethics camps in the country adjusted their training processes to protect and heal against drugs. The most famous camp at that time was Wat Chuchit Dhammaram, Wang Noi District, Phra Nakhon Si Ayutthaya Province organized by Phra Archarn Werapun Rukkitselo. Its main objective was training of lecturing monks to fight against drugs with project name of "Dhamma Force-Thai Force of Lecturing Monks against Drugs”. That was the origin of ethics camp.

After finishing training those lecturing monks adopted that camp management model for applying with their own camps. Moreover, there were many of camps as Wat Chonprathan Rangsarit at Nonthaburi
Province and Wat Punya Nuntaram, Klong Luang District, Pathum Thani Province directed by a great monk Punya Nunta Bhikkhu. Dhamma Tayart (Young Buddhist) Camp of Mahachulalongkornrajavidyalaya University and Mahamakut Buddhist University began to be famous with organizing of Buddha Putra-Buddha Dhamma Camp. Lecturing monks from both universities made their study trips and attended many camps and then brought those training courses back as guidelines to apply with their own ethics camps. The beginning of ethics camp was conformed to Cultural Diffusion Theory that said that a culture would be diffused to other places by social factors such as intentional cultural exchange, new behavior and knowledge, participation in religious rituals, studying from other sources. All of these were factors of cultural diffusion.

Current conditions and problems on providing of Ethics Camp for Northeastern Region Youth, Ecclesiastical Region 9: For personnel section, it was found that directors were supreme chairman of camps or abbots and had no problem on camp directors because they had long vision, distinct allocation of responsibilities for related persons, managed with Metta (kindheartedness), Karuna (mercy), Muthita (rejoicing with others in their prosperity) and Ubekkha (neutrality) as well as be a good example for their subordinates.

In aspect of lecturing monks, it was found that knowledge levels of some lecturing monks were rookies lacked of training skills and experiences. For their behaviors, it was found that some of them did not clearly understand objectives of Buddhism propagation in form of ethics camp. For their punctuality, it was found that some of them spent more time than their responsibilities. They had to warn each other for not postponing that caused further bad results on activities. For their psychological methods, it was found that some of them neither understood nor applied psychology to assist their training.

In aspect of personnel net study, it was found that net study of lecturing monk, teacher, student and government agency were not clear and lacked of integrated coordination.

In aspect of budget of supporting fund, it was found that there was insufficient supporting from both of private and government sectors. This conformed to studies of "Training Evalution on Persons who Passed Dhamma Successors Project of Cholpratan Rungsarit Temple, Pak KretDistrict, Nonthaburi Province”. They said that the most problem and obstacle of religious activities conducting was lacking of subsidies. Camps received only food and accommodation expenses from 


\section{J. Social Sci., 7 (2): 132-140, 2011}

schools that sent their students to camps. Government agencies placed low priority than material development that was concrete object. They ignored mind development that was the most important for human development. These also conformed to a study of "Training Evaluation on Buddha Putra Camp Project of Punyanuntaram Temple, Pathum Thani Province" it was found that there was no direct budgets from any state agencies and most of money only came from general Buddhists. For operation expenses, it was found that there was little problem in this point of sufficient budget in some school.

Materials: In aspect of training venues, it was found that they were problems about water leakage on roofs, many mosquitoes disturbed training especially in rainy season and some of mosquito wire screens were damaged. For accommodation, it was found that there was not individual one. For almshouses or kitchens, it was found that there was not enough compared with trainees' quantity. For toilets, it was found that there was not enough for trainees and some camp had its problem on draining system and cleanliness. For training equipments, it was found that some camps had ruined microphone as well as very thin of white clothes.

In aspect of course analysis, it was found that there was a changing of curriculum that made lecturing monks had to suddenly change their training course. There was no problem about course development. For trainee specification, it was found that each camp had its own rules and regulations but some students broke camp's rule by smoking in toilets, escaping from camps at night. For training operations, it was found that there was lacking of lecturing monks that imbalanced with high quantity of trainees in each month and sometime there were 2 courses in the same time that effected to training quality due to their tiredness. For training activities, it was found that some of trainees had no collaboration such as grateful activity needed peace and silence on meditation but some students did not pay attention by playing or making fun with their friends. For training equipments, it was found that amplifier, microphone and overhead projector were out of order because of its long services. This conformed to Piaget's Moral Development Theory said that teachers could upgraded moral development by assisting them to face with problems on moral conflict and training them to analyze, discuss, argue and determine. In higher level, teachers might present problems via media such as; pictures, slides, filmstrips or video tapes, roles playing and group processes. These would help learners to have more distinct understand and efficiency.
In aspect of public relation, it was found that overall of ethics camps had same problem about never had published documents about training courses or camps' background. In future, lecturing monks should have creative thinking to publish them. Furthermore, website of some camps was not updated that caused no new information.

In aspect of media production model, it was found that lecturing monks produced very few of technological media because they had no knowledge and time enough to produce modern technological media. Application and adaptation of media was not found in this study.

The appropriate management model of ethics camp for northeastern region youth, ecclesiastical region 9: In aspect of ethics camp directors, camp directors should have their characteristics as; having vision with wide thinking, long vision, knowledge seeking, systematic management thinking, going forward, daring to think, act, lead and follow. They should also have Dhamma principle of Ittibart 4, intelligence, good resolving of urgent problems, perseverance, patience, honesty, good human relationship and management by situation. These conformed to new management theories as; Contingency Theory with good planning, distinct studying target, training objectives setting, practical concept idea and concrete action planning. For organization, it was in accordance with role, authority, responsibility, recruitment, control, motivation, organization and self development as changed situations. These conformed to Radcliffe brown's structural functional Theory said that social had its structure like human body, each unit had its duty to study together for sustaining body and social. If social had some structural conflicts caused by malfunction of duties, it would effect to suspend or slow development. Finally, social would find itself with solution or structural adaptation for further development according to the suggestion of the study in many countries (Susana et al., 2004; Peter, 1992; Prathumnet et al., 2010; Buates et al., 2010).

In aspect of lecturing monks, good model of their knowledge level was they should pass some training courses, had both of secular and religious knowledge, had skills and studying experiences and professionalization. For pre training preparation, they should have meeting for planning, allocating of clear responsibilities. For training skill, they should have full of techniques with sense of humor and let trainees have their actual practice. The heart of training was let students having actual practices based on "Tri Sikkha of 


\section{J. Social Sci., 7 (2): 132-140, 2011}

Sil, Smathi and Punya" and "Ariya Marka" for their daily life application. For lecturing monks' behavior, they should be a good model with all of body, speech and mind both of before and behind; had good friendship and human relationship. These conformed to a research of "Monks' Role on Youth Ethics Development”, it was found that monks should properly apply Dhamma such as meditation for let youth to have peaceful mind and be generous to other persons. Moreover, monks should be models of good conduct. For their punctuality, they should come at least 10 minute before training class and on time finishing. For their psychological methods, they should recognize basic nature of trainees; understand they physical, mental and emotional development. Lecturing monks had to be believable and reliable.

In aspect of personnel net study, they were in models as flows; Net study of lecturing monks and camp directors should have methods to establish lecturing monks' net study by contacting them both of Phra Dhammaduta (Buddhist missionary monk), monks who taught moral in schools and others to participate with training as lecturing monks and to exchange their knowledge, skills and experiences for each other. A committee was appointed in each nets tudy consisted of chairman of lecturing monks net study, vice chairman, secretary, treasurer and member committee to coordinate mass for participating with training activities. These conformed to a research of "A Study on Development of Desirable Moral, Ethics and Value for Students in Basic educational Institutes under Ang Thong Educational Service Area Office”, it was found that development guideline by inviting parents and communities to participate in school's activities such as; participation in decision making, setting of desirable moral, ethics and value for students. This also conformed to a study of "Training Evaluation on Moral Training Project of Buddha Putra Camp at Punyanuntaram Temple, Klong Hok Sub district, Klong Luang District, Pathum Thani Province”, it was found that religious institutions, especially temples in community, should continually provided ethics promotion activities for youth in all areas. Educational institutions should cooperate with family and religious institutions to promote ethics and be good examples for youth. Other institutions as mass media should also participate with such institutions to promote ethics for you.

In aspect of budget or supporting fund, camps asked for budgets from communities as; provincial administrative organizations, sub district administrative organizations, municipalities, etchant also government sectors as; provincial Buddhism office and provincial culture office. Mass media were the most important group from inviting them to participate this project. After having budgets, fund or foundation should be established to keep for further financial management. Operation expenses should divide into 4 categories as; food expense about 30 baths/ head/ period and adjustment depended on economic situations, material expense and accommodation expense 3,500-4,000 baths for 2 nights 3 days and lecturing monks' expense depended on granters. For financial management, an accounting committee should be appointed with clear responsibilities, accounting system and bank account. For financial structure, if there was fund or foundation it should have distinct responsible persons with 2 of 3 members' signature for depositing or withdrawal.

In aspect of course analysis, good courses should have appropriateness of trainees' age, gender, maturity, environment, culture and requirement. Courses should be flexible with changing situations and especially could apply with daily life. These conformed to Bronislaw Malinowski's functionalism said that human always created things for their convenience and satisfaction. They would eliminate when they felt inconvenient and dissatisfactory with those things and new things which be better and more proper would be created instead for further functioning. These were not different from a study of "Problem Conditions and Guideline for Learning Arrangement Promotion on development of desirable moral, ethics and Value for Students in Buddhism Oriented Schools under Sing Buri Educational Service Area Office”, it was found that it should have been regularly provided with policies and coproject plan and also regularly provided students with ethics promotion activities. These activities should have variety and inserted with ethics and morality as well as having evaluation. These conformed to an independent study of "Development of Moral and Ethics for Junior High School Students by Mind Development Project in Chaing Yuen District, Mahasarakham Province" that activity of Mind Development Project spent for 3 days with its objective to let group of co-researcher and target group having Buddha Dhamma appreciation, to be orderly and disciplinary and to avoid drugs.

For course development, main objective of each course was training students to be good persons that this world needed, with respect, discipline and patience. Smart persons that this world needed were those who could apply the heart of philosopher; "Su, Ji, Pu and Li: listening, thinking, questioning and writing" and "Tri Sikkha of Sil, Smathi and Punya” with their daily life. In aspect of courses content determination, cultural aspect should be low staying but high action. Low 
staying meant having low profile of living while high action emphasized on importance of etiquette with gentleness both of body and words. Gentle mind was consisted of 6 things as; punctuality, sweet words, giving help, having good thinking, be modest and know how to desert for good future. For ethics and morality, there were 7 categories of ethics as; avoiding 4 kinds of bad conduct, avoiding 4 kinds of bias, avoiding 6 kinds of bad allurement, know how to separate true or fake friends, know how to find asset with honesty and correctness, saving and careful spending, conducting own duties according to social status and relationship and complying with principle of Sanggaha Wattu 4 (4 objects of sympathy). There were 7 categories of morality as; patience, perseverance, thriftiness, honesty, discipline and far from bad things. Principle of 5 good for better life were; good thinking, good speaking, good acting, good friend and good place. These were methods and goals to develop complete human for being "good child of parents, good student of teacher, good fellow of friend, good youth of the country and good religion follower of Buddhism". These conformed to a research of "Patterns of Educational Arrangement and Buddhist Mission of Buddhist Temples: Case Study of Punyanuntaram Temple, Klong Luang District, Pathum Thani Province", it was found that Buddhist path was used as the main core of course management. Religious culture was to conduct 8 commandments and strictly follow with all rules and also clung to Phra Punya Nunta Bhikkhu' s principle of 5 good for better life; good thinking, good speaking, good acting, good friend and good place. In aspect of activity, it should focus on the heart of philosopher; "Su, Ji, Pu and $\mathrm{Li}$ : listening, thinking, questioning and writing." For trainee's qualifications were as example; those who had permitted from their parents or guardians by written, could attend camp/observed the 5 or 8 precepts all over project. Training courses had to stress on being good example, good human relationship and good friend of all lecturing monks. Training activities focused on the heart of philosopher; "Su, Ji, Pu and Li: listening, thinking, questioning and writing” that meant all trainees had their participation on all activities by actual practices.

In aspect of trainees' requirements, courses should have flexibility in accordance with situations and incidents, modernity, attractiveness and met trainees' requirements. Services, director and lecturing monks should provided trainees with aspects of service such as; warm welcoming, gentle speaking, good relationship and friendliness as well as provided them with liaisons for training and public relation. Lecturing monks had to have public relation with villagers, communities and related agencies for their acknowledgement about those Ethics Camp Projects according to the previous study (Hanes et al., 2003; Komolmas, 2007). Moreover, camps should propagate their activities via brochures, books, pamphlets, magazines, community radios and internet. These conformed to a research of "Education that Temples Use for Buddhist Mission: Case Study of Temples in Mueang District, Nakhon Pathom Province”, it was found that Buddhism propagation must use media as radio, television, document and proving activities on famous days of Buddhism.

In aspect of media production model, it had main composition as; production planning was consisted of content specification, extending details of each content and arranging stories related to content; media production lecturing monks should analyze on media efficiency and cost effectiveness; finding media efficiency was consisted of experimental using step by step for evaluation, using gained results for improvement and final implementation. These were under 3 principles of finding media efficiency. The first was criteria of finding media efficiency and stops of testing on finding media efficiency. The second was media application, lecturing monks should appropriately analyze, edit and use by consideration of contents. Those media must relate to contents for easy understanding, awareness and maximized benefit. Finally, media implementation should consider about the appropriateness of trainees' age, gender, maturity and requirement as well as media analyzing by open first before using to avoid sequent mistakes.

\section{CONCLUSION}

The purpose of this study was to study backgrounds, current conditions, problems on management and the appropriate management model of Ethics Camp for the Northeastern Region Youth, Ecclesiastical Region 9 of Thailand. The study was a qualitative research conducted in 4 provinces 1 place for each; Khon Kaen at Weruwan Meditation Center, Mahasarakham at Wat Sri Sawat, Kalasin at Wat Pracha Niyom and Roi Et at Wat Pa Nong Mong Buraparam. Samples were 164 persons; consisted of key informants, casual informants and general informants; selected by purposive sampling method. Observation form, survey form, interview form, focus group discussion and study shop were used as research tools. Triangulation was used to test all data and data was analyzed by descriptive research. The study revealed that background of Ethics Camp for Northeastern Region Youth, Ecclesiastical Region 9 in 
overall of 4 places were began by making study trips of directors or lecturing monks at famous camp as; Wat Chuchit Dhammaram, Phra Nakhon Si Ayutthaya and Buddha Puttra Camp at Wat Punya Nuntaram, Pathum Thaniand they, later, brought those models back to establish ethics camps in their own provinces.

For current conditions and problems on providing of Ethics Camp, in aspect of personnel there was lacking of competent personnel, lacking of budget for expenses and some place had old and damaged equipments. There were not enough budgets for long term training and also lacking of lecturing monks, lacking of public relation and distinct documents of courses and lecturing monks had no knowledge to produce modern technological media.

The appropriate management model, camp directors should have wide and long vision, intelligence, perseverance, honesty and human relation while lecturing monks must be professional. The charges for any expenses should be depended on situations and should be in form systematic study with committees and asked for supporting from related agencies. The materials should have safety, cleanliness and peace that was good environment for training while training equipments should be modern, attractive and met requirements of trainees and should analyze the appropriateness of trainees' age, maturity and requirement, course development and other subjects should be integrated into training courses, training operation. For marketing, should provide services with friendliness and publicized camps in websites.

In conclusion, Ethics Camp for Northeastern Region Youth, Ecclesiastical Region 9 should be cooperated by all net study to support youth for attending ethics camp to develop their better quality of life.

\section{REFERENCES}

Buates, D., S. Chantachon, K. Paengsoi and A. Kangrang, 2010. Monks' health: holistic health care model by community participation. J. Soc. Sci., 6: 478-482. DOI: $10.3844 /$ jssp.2010.478.482

Hanes, C., E.M. Rife and L.B. Laguna, 2003. The impact of a summer camp program as a secondary prevention measure for at-risk youth, crime prevention and community safety. Int. J., 7: 37-49. DOI: 10.1057/palgrave.cpcs.8140223

Komolmas, M., 2007. Ethics, moral and social responsibility formation of students: Contemporary challenges for catholic schools in Thailand, international handbook of catholic education. Int. Handbooks Religion Edu., 2: 725-736. DOI: 10.1007/978-1-4020-5776-2_38
Laomi, B., S. Chantachon and N. Wongphongkham, 2009. A model of pulpit conservation and revitalization using community participation of phu-thai people in Northeast Thailand. J. Soc. Sci., 5: 374-376. DOI : 10.3844/jssp.2009.374.376

Peter, C.B., 1992. Collections storage I: Storage of ecclesiastical textiles in Lyon. Museum Manage. Curatorship, 11: 212-213. DOI: 10.1016/09647775(92)90031-Y

Poo-Inna, S., S.K. Jantakajon and T. Pantachai, 2009. Appropriate model for zoning local fish conservation in front of buddhist temple on the bank of the chi river by sustainable community participation. J. Soc. Sci., 5: 411-415. DOI: 10.3844/jssp.2009.411.415

Prathumnet, N., S. Chantachon, K. Paengsoi, N. Thongwol and B. Saenyabud, 2010. An application of indigenous knowledge for conservation and development of the production process of silk cloths. J. Soc. $\quad$ Sci., 6 : 330-332. DOI: 10.3844/jssp.2010.330.332

Suksri, A., S. Phothisane, S. Laoakka, N. Thongwol and B. Saenyabud, 2010. The buddha images and conservation and adherence to cultural values in Northeast. J. Soc. Sci., 6: 320-323. DOI : 10.3844/jssp.2010.320.323

Susana, E., V. Jorge, G.M.E. Howell and R.D.S. Mark, 2004. Lichen biodeterioration of ecclesiastical monuments in northern Spain, spectrochimica acta part A. Molecular Bio. Spectrosc., 60: 1229-1237. DOI: 10.1016/j.saa.2003.08.005 